Editorial

\title{
The 2030 Agenda for Sustainable Development: Transformative Change through the Sustainable Development Goals?
}

\author{
Sabine Weiland ${ }^{1, *}$, Thomas Hickmann ${ }^{2}$, Markus Lederer ${ }^{3}$, Jens Marquardt ${ }^{3}$ \\ and Sandra Schwindenhammer ${ }^{4}$ \\ ${ }^{1}$ European School of Political and Social Sciences, Lille Catholic University, 59000 Lille, France; \\ E-Mail: sabine.weiland@univ-catholille.fr \\ ${ }^{2}$ Copernicus Institute of Sustainable Development, Utrecht University, 3584 CB Utrecht, The Netherlands; \\ E-Mail: t.hickmann@uu.nl \\ 3 Institute of Political Science, Technical University Darmstadt, 64293 Darmstadt, Germany; \\ E-Mails: lederer@pg.tu-darmstadt.de (M.L.), jens.marquardt@tu-darmstadt.de (J.M.) \\ ${ }^{4}$ Department of Political Science, Justus Liebig University Giessen, 35394 Giessen, Germany; \\ E-Mail: sandra.schwindenhammer@sowi.uni-giessen.de \\ * Corresponding author
}

Submitted: 15 February 2021 | Published: 26 February 2021

\begin{abstract}
The 2030 Agenda of the United Nations comprises 17 Sustainable Development Goals (SDGs) and 169 sub-targets which serve as a global reference point for the transition to sustainability. The agenda acknowledges that different issues such as poverty, hunger, health, education, gender equality, environmental degradation, among others, are intertwined and can therefore only be addressed together. Implementing the SDGs as an 'indivisible whole' represents the actual litmus test for the success of the 2030 Agenda. The main challenge is accomplishing a more integrated approach to sustainable development that encompasses new governance frameworks for enabling and managing systemic transformations. This thematic issue addresses the question whether and how the SDGs set off processes of societal transformation, for which cooperation between state and non-state actors at all political levels (global, regional, national, sub-national), in different societal spheres (politics, society, and economy), and across various sectors (energy, transportation, food, etc.) are indispensable. In this editorial, we first introduce the 2030 Agenda and the SDGs by providing an overview of the architecture of the agenda and the key challenges of the current implementation phase. In a second step, we present the eleven contributions that make up the thematic issue clustering them around three themes: integration, governance challenges, and implementation.
\end{abstract}

\section{Keywords}

2030 Agenda; governance; implementation; integration; Sustainable Development Goals; sustainability; transformation; transition; United Nations

\section{Issue}

This editorial is part of the issue "The 2030 Agenda for Sustainable Development: Transformative Change through Sustainable Development Goals?" edited by Thomas Hickmann (University of Utrecht, The Netherlands), Markus Lederer (Technical University of Darmstadt, Germany), Jens Marquardt (Technical University of Darmstadt, Germany), Sandra Schwindenhammer (Justus Liebig University Giessen, Germany) and Sabine Weiland (Catholic University of Lille, France).

(C) 2021 by the authors; licensee Cogitatio (Lisbon, Portugal). This editorial is licensed under a Creative Commons Attribution 4.0 International License (CC BY). 


\section{The 2030 Agenda and the Sustainable Development Goals}

In September 2015, the international community adopted a global sustainable development agenda, the 2030 Agenda for Sustainable Development (2030 Agenda), at the United Nations General Assembly. It comprises 17 Sustainable Development Goals (SDGs) and 169 detailed sub-targets with which the 'transformation of our world' towards a fairer and more peaceful future is to be set in motion (United Nations, 2015). Building upon the Millennium Development Goals (MDGs) adopted in 2000, the 2030 Agenda calls on each member state of the United Nations to implement the 17 SDGs and the associated sub-targets in their own country and to support goal implementation in all other parts of the world by 2030 . In doing so, the international community aims to overcome the North-South divide that still prevails in global environmental and development politics.

\subsection{The Architecture of the 2030 Agenda}

The 2030 Agenda acknowledges that different issues such as poverty, hunger, health, education, gender equality, environmental degradation, etc., are intertwined. As such, the 17 SDGs form an integrated system, i.e., they recognise that action in one area will affect outcomes in others and that sustainable development must balance social, economic, and environmental aspects (Nilsson, Griggs, \& Visbeck, 2016). The previous eight MDGs focused on development goals, targeting primarily developing countries, with more advanced countries providing financial and technological assistance. In contrast to that, the SDGs are thematically and spatially more comprehensive and apply to all countries. To achieve them, a concerted global effort for the wellbeing of the current and the following generations and more integrated and cross-sectoral policies are needed (Sachs, 2012; Sachs et al., 2019).

The 'indivisible' 2030 Agenda responds to the lessons learned from the MDG process and its problems arising from fragmentation and siloed implementation (Vandemoortele, 2011; Waage et al., 2015). A focus on interlinkages between policy areas is perceived as indispensable and as an opportunity to realise positive interactions between the SDGs and ensure that progress achieved in some areas is not made at the expense of progress in others. These linkages, which can be both implicit and explicit, are already built into the SDGs architecture. For example, the aims of SDG 3 ('good health and wellbeing') can be found across other goals, such as SDG 1 ('no poverty'), SDG 2 ('zero hunger'), SDG 6 ('clean water and sanitation'), and SDG 10 ('reduced inequalities') (ICSU, 2017). The SDGs were therefore qualified as a 'network of targets' (Le Blanc, 2015), in which interactions can be positive, i.e., progress in one goal favours progress in another ('synergies'), or negative, i.e., progress in one goal hinders progress in anoth- er ('trade-offs'; Pradhan, Costa, Rybski, Lucht, \& Kropp, 2017). This architecture opens up perspectives for crosssectoral and integrated implementation but simultaneously presents new coordination challenges for governments, donors, civil society representatives, and other relevant political and societal actors.

Closely connected to the theme of interactions is the notion of partnership for implementation. SDG 17 explicitly focusses on 'strengthening the means of implementation and revitalising the global partnership for sustainable development.' It highlights that 'effective public, public-private and civil society partnerships' (United Nations, 2015, Target 17.17) may lead to the institutions and governance structures needed to foster comprehensive SDG implementation. A broad range of state and non-state actors is regarded as institutional agents with the potential for policy change. They invest time, issuespecific expertise, and skills to promote certain policies and strategically act as "meaning managers" by creating new cognitive frames, thus establishing "new ways of talking about and understanding issues" (Finnemore \& Sikkink, 1998, p. 897). These actors often represent specific policy issues and objectives. Building partnerships between them is therefore not only a means to foster cooperation to achieve the SDGs, but also to understand how interactions look like between the policy issues or sectors they represent (Horan, 2019; Stibbe \& Prescott, 2020). A second principle for turning the potential of SDG interactions into reality is SDG 16 ('peace, justice and strong institutions'), which underlines the importance of 'good governance.' Good governance promotes accountability, transparency, efficiency, and the rule of law at all levels, as well as efficient management of human, natural, and economic resources for sustainable development (Monkelbaan, 2019, Chapter 7). The key question is how to establish such institutions needed for implementing the 2030 Agenda, given the diverse institutional and normative settings that exist among nation-states.

\subsection{Transformative Change through the SDGs?}

The 2030 Agenda and the SDGs serve as a global reference point for the transition to sustainable development. They call for the transformation of existing institutional structures in every country and require a concerted effort of governments at multiple levels, civil society, business, and academia. The 'governance through goals' approach (Biermann, Kanie, \& Kim, 2017; Fukuda-Parr, 2014; Kanie \& Biermann, 2017) is characteristic of the 2030 Agenda and the SDGs. It relies on goal-setting instead of rule-based governance, while concretisation and implementation of the SDGs are left to the actors at various governance levels. Implementing the SDGs thus represents the actual litmus test for the success of the 2030 Agenda. To achieve the goals, processes of radical societal transformation are necessary. These require support through cooperation between state and non-state 
actors at all political levels (global, regional, national, sub-national), in different societal spheres (politics, society, and economy), and across various sectors (energy, transportation, food, etc.).

The seeds of transformation are sown with the SDGs-but their flourishing depends on how global ambitions are translated into national contexts and adapted to their priorities, to which extent national governments formally commit themselves to the goals, and how agents of change can be mobilised. The collaborative governance architecture builds on support and interaction, similar to the hybrid and dispersed post-Paris climate governance (Kuyper, Linnér, \& Schroeder, 2018). The main challenge is implementing a more integrated approach to sustainable development that encompasses new governance frameworks for enabling and managing systemic transformations. One strategy is to exploit the co-benefits between the goals by identifying those with critical leverage to achieve and accelerate systemic sustainability gains. Identifying them requires in-depth analyses to map out interdependencies between SDG outcomes (Kroll, Warchold, \& Pradhan, 2019; Nilsson et al., 2018).

In this context, "The World in 2050," a global research initiative launched by the International Institute for Applied Systems Analysis, the Sustainable Development Solutions Network, and the Stockholm Resilience Centre, proposes six transformations in different thematic clusters for achieving the SDGs and long-term sustainability: (1) education, gender and inequality, (2) health, wellbeing and demography, (3) energy decarbonisation and sustainable industry, (4) sustainable food, land, water and oceans, (5) sustainable cities and communities, and (6) a digital revolution for sustainable development (TWI2050, 2018). The strategy to rely on modular transformations is an attempt to take a holistic perspective that integrates all possible domains affected while at the same time simplifying the complex interlinkages, and concomitant interventions, in the SDG system (Sachs et al., 2019). The Global Sustainable Development Report 2019 (UN Department for Economic and Social Affairs, 2019) proposes a similar transformation strategy.

Sustainability transformations require new governance frameworks, tools, and institutions to address the enormous and complex societal challenges posed by the 2030 Agenda. In this thematic issue, we shed light on these challenges by taking stock of current debates and actions in implementing the SDGs and achieving societal and global change and transformation.

\section{The Contributions to the Thematic Issue}

The contributions in this thematic issue represent a spectrum of perspectives on the 2030 Agenda, the SDGs and their transformative potential. The volume includes conceptual and normative contributions to the debate as well as more empirical ones focussing on the governance and implementation of the 2030 Agenda. The arti- cles in this thematic issue can broadly be grouped into three parts.

\subsection{The SDGs as an 'Indivisible Whole': Integration, Coherence, and Justice}

The first set of articles analyse the SDGs as an 'indivisible whole' - a system of interlinked goals that can only be achieved together. The authors come to rather different conclusions depending on the perspective they take. The contribution by Bornemann and Weiland (2021) investigates the notion of policy integration in the context of the 2030 Agenda against the background of the historical sustainability discourse. While the latter was dominated by the concept of environmental policy integration, the 2030 Agenda promotes an encompassing, reciprocal, and complex integration approach. Priority goals can still be identified and serve as leverage points for improving the overall goal system. Brand, Furness, and Keijzer (2021) criticise the 2030 Agenda's focus on policy coherence as a form of technocratic believe in the manageability of the complex relations between the SDGs. The authors argue that despite the emphasis of integration, the underlying political interests of different actors will remain fundamentally incompatible, which in turn makes navigating political trade-offs pivotal for achieving the SDGs. The article by Müller, Neumann, Elsner, and Claar (2021) comes to a similar conclusion from an empirical case study that examines the notion of justice as a means to address trade-offs and enhance co-benefits in the implementation of the SDGs. Using the African energy transition as an example, progress towards SDG 7 ('affordable and clean energy') is examined with a focus on integrating an energy justice dimension to align socio-ecological requirements and people's energy needs. Finally, Konold and Schwietring's (2021) contribution addresses the discrepancy between the ambitions of the 2030 Agenda and sustainable development, and the change that is actually achieved. It is argued that this gap is not rooted in a lack of political will or strategy but rather due to the specific functional logics of the different social subsystems which have to be taken into consideration in the transformation of society towards sustainability.

\subsection{Challenges for SDG Governance: Norm Interpretation, Partnership, Science and Technology}

The contributions of the second part revolve around the governance challenges that the 2030 Agenda and the SDGs pose. Breitmeier, Schwindenhammer, Checa, Manderbach, and Tanzer (2021) analyse the heterogenous norm interpretations of sustainability in the context of SDG 2 ('zero hunger') that can potentially impede its implementation. Based on the literature on global regime complexes, the authors focus on inter-institutional arrangements which provide discursive exchange fora to facilitate cooperation, and thus 
have great potential to achieve more aligned sustainability norm understandings. Sondermann and Ulbert (2021) take SDG 17 ('partnerships for the goals') as a starting point of their contribution. They develop partnership as a form and norm of meta-governance of the SDGs, which they operationalise along different levels of accountability and participation, as proxies for the quality of partnership. The study applies this framework to the implementation of the health-related goals of the 2030 Agenda. The contribution by Zeigermann (2021) examines strategies of scientific knowledge integration adopted by science-based actor networks with the aim to enhance the evidence base of sustainability governance. The analysis of national Sustainable Development Solution Networks (SDSNs) reveals that these strategies-be they solution-oriented, assessmentoriented, or learning-oriented strategies-are shaped by the interaction of the network actors with their institutional environment. Finally, Schwindenhammer and Gonglach (2021) study technology as a pillar for SDG implementation. In a case study of a wastewater treatment system in urban agricultural production in Germany, the authors find that the emerging technology has potential to facilitate the implementation of SDG 2, while simultaneously posing new challenges for more integrated policymaking to govern the food-watertechnology nexus.

\subsection{Implementing the SDGs across Different Governance Levels}

The contributions of the third part examine the implementation of the SDGs across different governance levels. Bornemann and Christen (2021) discuss the implementation of the 2030 Agenda with a focus on the Swiss subnational governance context. Governments and administrations have over the past decades developed differentiated sustainability governance arrangements (SGAs) which are now confronted with the new challenges that SDG implementation poses. The analysis carves out the possibilities and limitations of the existing SGAs to meet the requirements of the 2030 Agenda. Krellenberg and Koch (2021) analyse sustainability transformation at the city level. In the context of the current COVID-19 pandemic, they explore the potentials and contradictions in implementing SDG 11 ('sustainable cities and communities') that result from the multiple tasks, actors involved, and complexity of sustainability transformations. The final contribution by Hickmann (2021) takes as a starting point the high expectations that have recently been put on the role of cities and their governments in the global endeavour to achieve sustainability worldwide. The author, in contrast, argues that urban sustainability actions are embedded in complex interactions between public and private actors, and across different governance levels. A multi-level governance approach is therefore necessary, acknowledging the interconnectedness of cities, which implies poten- tials and limitations for governing and implementing the 2030 Agenda at the local level.

The contributions to this thematic issue, while focusing on different conceptual and empirical dimensions and topics of the SDGs, share the common goal of shedding light on the transformation induced by the 2030 Agenda. They point to fundamental challenges in the design, elaboration, and implementation of the SDGs, and emphasise the large potential of the 2030 Agenda to foster change. Five years after adopting the SDGs and their transformative agenda, we hope that this volume contributes to further elucidating this ambitious programme and the various implications of putting sustainable development into practice.

\section{Acknowledgments}

We would like to thank the participants of the conference "The Sustainability Agenda of the United Nations: Concept, Evolution and Impact of the Sustainable Development Goals," organised by the Working Group Environmental Policy/Global Change of the German Political Science Association and the Schader Foundation on 5-6 March 2020 in Darmstadt, Germany, where the idea to this thematic issue was born. Special thanks go to all contributing authors of this thematic issue and to the anonymous reviewers that delivered constructive and detailed feedback on earlier versions of the published articles.

\section{Conflict of Interests}

The authors declare no conflict of interests.

\section{References}

Biermann, F., Kanie, N., \& Kim, R. E. (2017). Global governance by goal-setting: The novel approach of the UN sustainable development goals. Current Opinion in Environmental Sustainability, 26/27, 26-31.

Bornemann, B., \& Christen, M. (2021). A new generation of sustainability governance: Potentials for 2030 Agenda implementation in Swiss cantons. Politics and Governance, 9(1), 187-199.

Bornemann, B., \& Weiland, S. (2021). The UN 2030 Agen$\mathrm{da}$ and the quest for policy integration: A literature review. Politics and Governance, 9(1), 96-107.

Brand, A., Furness, M., \& Keijzer, N. (2021). Promoting policy coherence within the 2030 Agenda framework: Externalities, trade-offs and politics. Politics and Governance, 9(1), 108-118.

Breitmeier, H., Schwindenhammer, S., Checa, A., Manderbach, J., \& Tanzer, M. (2021). Aligned sustainability understandings? Global inter-institutional arrangements and the implementation of SDG 2. Politics and Governance, 9(1), 141-151.

Finnemore, M., \& Sikkink, K. (1998). International norm dynamics and political change. International Organi- 
zation, 52(4), 887-917.

Fukuda-Parr, S. (2014). Global goals as a policy tool: Intended and unintended consequences. Journal of Human Development and Capabilities, 15(2/3), 118-131.

Hickmann, T. (2021). Locating cities and their governments in multi-level sustainability governance. Politics and Governance, 9(1), 211-220.

Horan, D. (2019). A new approach to partnerships for SDG transformations. Sustainability, 11(18). https:// doi.org/10.3390/su11184947

ICSU. (2017). A guide to SDG interactions: From science to implementation. Paris: International Council for Science.

Kanie, N., \& Biermann, F. (Eds.). (2017). Governing through goals: Sustainable development goals as governance innovation. Cambridge, MA: MIT Press.

Konold, D., \& Schwietring, T. (2021). The great discrepancy: Political action, sustainable development and ecological communication. Politics and Governance, 9(1), 131-140.

Krellenberg, K., \& Koch, F. (2021). Conceptualizing interactions between SDGs and urban sustainability transformations in Covid-19 times. Politics and Governance, 9(1), 200-210.

Kroll, C., Warchold, A., \& Pradhan, P. (2019). Sustainable development goals (SDGs): Are we successful in turning trade-offs into synergies? Palgrave Communications, 5(1). https://doi.org/10.1057/s41599-0190335-5

Kuyper, J. W., Linnér, B. O., \& Schroeder, H. (2018). Nonstate actors in hybrid global climate governance: Justice, legitimacy, and effectiveness in a post-Paris era. Wiley Interdisciplinary Reviews: Climate Change, 9(1), 1-18.

Le Blanc, D. (2015). Towards integration at last? The sustainable development goals as a network of targets. Sustainable Development, 23, 176-187.

Monkelbaan, J. (2019). Governance for the sustainable development goals. Exploring an integrative framework of theories, tools, and competencies. Singapore: Springer.

Müller, F., Neumann, M., Elsner, C., \& Claar, S. (2021). Assessing African energy transitions: Renewable energy policies, energy justice, and SDG 7. Politics and Governance, 9(1), 119-130.

Nilsson, M., Chisholm, E., Griggs, D., Howden-Chapman, P., McCollum, D., Messerli, P., . . . Stafford-Smith, M. (2018). Mapping interactions between the sustainable development goals: Lessons learned and ways forward. Sustainability Science, 13, 1489-1503.

Nilsson, M., Griggs, D., \& Visbeck, M. (2016). Policy: Map the interactions between sustainable development goals. Nature, 534(7607), 320-322.

Pradhan, P., Costa, L., Rybski, D., Lucht, W., \& Kropp, J. P. (2017). A systematic study of sustainable development goal (SDG) interactions. Earth's Future, 5, 1169-1179.

Sachs, J. D. (2012). From millennium development goals to sustainable development goals. Lancet, 379(9832), 2206-2211.

Sachs, J. D., Schmidt-Traub, G., Mazzucato, M., Messner, D., Nakicenovic, N., \& Rockström, J. (2019). Six transformations to achieve the sustainable development goals. Nature Sustainability, 2, 805-814.

Schwindenhammer, S., \& Gonglach, D. (2021). SDG implementation through technology? Governing foodwater-technology nexus challenges in urban agriculture. Politics and Governance, 9(1), 176-186.

Sondermann, E., \& Ulbert, C. (2021). Transformation through 'meaningful' partnership? SDG 17 as metagovernance norm and its global health implementation. Politics and Governance, 9(1), 152-163.

Stibbe, D., \& Prescott, D. (2020). The SDG partnership guidebook. A practical guide to building high impact multi-stakeholder partnerships for the sustainable development goals. Oxford: The Partnering Initiative and UNDESA

TWI2050. (2018). Transformations to achieve the sustainable development goals. Laxenburg: International Institute for Applied Systems Analysis. Retrieved from http://pure.iiasa.ac.at/15347

UN Department for Economic and Social Affairs. (2019). Global sustainable development report 2019. New York, NY: UN Department of Economic and Social Affairs.

United Nations. (2015). Transforming our world: The 2030 Agenda for sustainable development (A/RES/70/1). New York, NY: UN General Assembly. Retrieved from https://sdgs.un.org/2030agenda

Vandemoortele, J. (2011). If not the millennium development goals, then what? Third World Quarterly, 32(1), 9-25.

Waage, J., Yap, C., Bell, S., Levy, C., Mace, G., Pegram, T., . . Poole, N. (2015). Governing the UN sustainable development goals: Interactions, infrastructures, and institutions. The Lancet Global Health, 3(5), e251-e252.

Zeigermann, U. (2021). Scientific knowledge integration and the implementation of the SDGs: Comparing strategies of sustainability networks. Politics and Governance, 9(1), 164-175. 


\section{About the Authors}

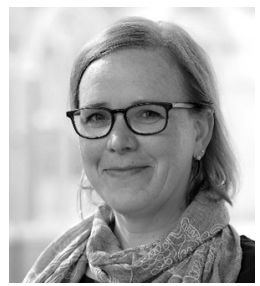

Sabine Weiland is Associate Professor of Political Science at Lille Catholic University, affiliated with the European School of Political and Social Sciences (ESPOL). She is the Director of the ESPOL-LAB Research Centre for European and International Politics. Her research focusses on sustainable development and transformation of society, reflexive governance, food politics, environmental politics, and the role of knowledge in political processes.

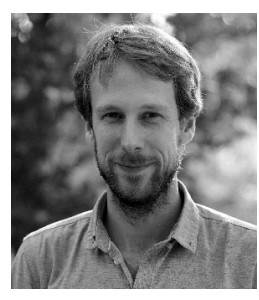

Thomas Hickmann is a Researcher with the Copernicus Institute of Sustainable Development at the Faculty of Geosciences, Utrecht University in the Netherlands. He is a core team member of the GlobalGoals project focusing on the steering effects of the United Nations Sustainable Development Goals and co-leads the Working Package 2.3 in the H2020 ENGAGE project on international constraints and enablers of decarbonization.

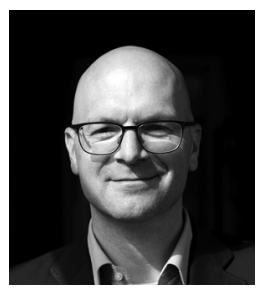

Markus Lederer is a Professor of Political Science with a focus on International Relations at the Department of Political Science at Technical University Darmstadt in Germany since 2016. His research focuses on global climate politics and green transformations in the global South.

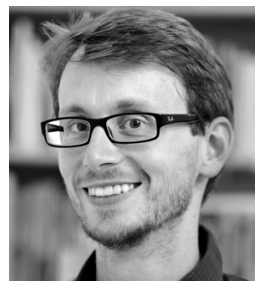

Jens Marquardt is a Research Associate at the Department of Political Science at Technical University Darmstadt. With a background in political science and science \& technology studies (STS), his research interests revolve around environmental governance, climate politics, and development. He is currently committed to a joint DFG research project on the institutionalization of climate change mitigation efforts in the Global South.

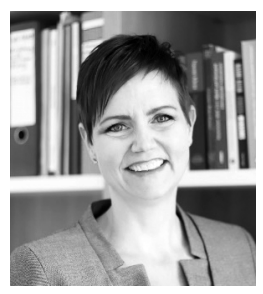

Sandra Schwindenhammer is Assistant Professor of International Relations at Justus Liebig University Giessen, Germany. She is Co-Principal Investigator for the collaborative research project 'SUSKULTDevelopment of a Sustainable Cultivation System for Food in Resilient Metropolitan Regions' (2019-2022) funded by the German Federal Ministry of Education and Research and Speaker of the Working Group Environmental Politics and Global Change of the German Political Science Association. Her areas of expertise involve global norms, norm entrepreneurship, and agri-food and sustainability politics. 